Vol 10, Issue 11, 2017

\title{
SIMULTANEOUS SPECTROPHOTOMETRIC DETERMINATION OF DICLOFENAC SODIUM, PARACETAMOL, AND CHLORZOXAZONE IN TERNARY MIXTURE USING CHEMOMETRIC AND ARTIFICIAL NEURAL NETWORKS TECHNIQUES
}

\author{
RAMZIA I EL-BAGARY ${ }^{1}$, EHAB F EL-KADY², AHMED A AL-MATARI ${ }^{3 *}$ \\ ${ }^{1}$ Department of Pharmaceutical Chemistry, Faculty of Pharmacy, Future University, New Cairo, Egypt. ${ }^{2}$ Department of Pharmaceutical \\ Chemistry, Faculty of Pharmacy, Cairo University, Kasr El-Aini St., Cairo, Egypt. ${ }^{3}$ Department of Pharmaceutical Chemistry, Faculty of \\ Pharmacy, Sana'a University, Sana'a, Yemen. Email: ahmedalmatari76@gmail.com
}

Received: 05 June 2017, Revised and Accepted: 27 July 2017

\section{ABSTRACT}

Objective: The aim of this study is to develop and validate simple, accurate, and precise spectrophotometric methods for the simultaneous determination of diclofenac sodium (DIC), paracetamol (PAR), and chlorzoxazone (CHZ) in ternary mixture using chemometric and artificial neural networks (ANN) techniques.

\begin{abstract}
Methods: Three chemometric techniques include classical least squares (CLS), principal component regression (PCR), and partial least squares (PLS) in addition to cascade-forward backpropagation ANN (CFBP-ANN) were prepared using the synthetic mixtures containing the three drugs in methanol. In CLS, PCR, and PLS, the absorbances of the synthetic mixtures in the range $267-295 \mathrm{~nm}$ with the intervals $\Delta \lambda=0.2 \mathrm{~nm}$ in their zero-order spectra were selected. Then, calibration or regression was obtained using the absorbance data matrix and concentration data matrix for the prediction of the unknown concentrations of DIC, PAR, and CHZ in their mixtures. In CFBP-ANN, two layers, sigmoid layer with 10 neurons and linear layer were found appropriate for the simultaneous determination of the three drugs in their ternary mixture.
\end{abstract}

Results: The four proposed methods were successfully applied to the analysis of the three drugs in laboratory prepared mixtures and tablets with good percentage recoveries in the range of $98-102 \%$. Relative standard deviation for the precision study was found $<1 \%$.

Conclusion: The four proposed methods showed simplicity, accuracy, precision, and rapidity making them suitable for quality control and routine analysis of the cited drugs in ternary mixtures and pharmaceutical formulation containing them.

Keywords: Diclofenac sodium, Paracetamol, Chlorzoxazone, Chemometrics, Artificial neural networks.

(C) 2017 The Authors. Published by Innovare Academic Sciences Pvt Ltd. This is an open access article under the CC BY license (http://creativecommons. org/licenses/by/4. 0/) DOI: http://dx.doi.org/10.22159/ajpcr.2017.v10i11.20491

\section{INTRODUCTION}

Diclofenac sodium (DIC), sodium [2-(2,6-dichloroanilino) phenyl] acetate (Fig. 1a), is a derivative of phenylacetic acid classed as a non-steroidal anti-inflammatory drug, used to relieve the pain and inflammation in many conditions such as rheumatoid arthritis, osteoarthritis, and ankylosing spondylitis [1,2]. Paracetamol (PAR), $\mathrm{N}$-acetyl-p-aminophenol (Fig. 1b), is an analgesic and antipyretic agent with weak anti-inflammatory property. It is used for the management of mild-to-moderate pain and fever [1,3]. Chlorzoxazone (CHZ), 5-chlorobenzoxazol-2(3H)-one (Fig. 1c), is a centrally acting skeletal muscle relaxant with sedative properties, used as an adjunct in the symptomatic treatment of painful skeletal muscle conditions [1].

The combination of the three drugs is widely prescribed for the alleviation of the pain associated with the muscle spasm.

Literature survey reveals that several methods have been reported for the determination of DIC in pharmaceutical and biological samples. These methods include spectrophotometry and multivariate [4-6], fluorimetry $[7,8]$, voltammetry $[9,10]$, high-performance liquid chromatography-ultraviolet (HPLC-UV) [11-15], liquid chromatographytandem mass spectrometry (LC-MS/MS) [16-19], capillary zone electrophoresis [20], and densitometry [21,22]. Other methods were developed for the simultaneous determination of DIC in binary combination with PAR or CHZ that include spectrophotometry [23-25], densitometry [26], voltammetry [27], and HPLC-UV [28,29]. Some methods were reported for the simultaneous determination of ternary combination of the three drugs based on densitometry [30,31] and HPLC-UV [32,33].

The UV absorption spectra of DIC, PAR, and CHZ in methanol at concentrations corresponding to their ratio in the combined dosage form reveal strong overlap (Fig. 2). Thus, direct simultaneous spectrophotometric determination of the three drugs in the mixture is not feasible. To the best of our knowledge, no previous spectrophotometric method based on chemometric techniques and artificial neural networks (ANN) has been published for the simultaneous determination of the three drugs. Thus, the main aim of this work was to develop and validate simple and accurate spectrophotometric methods for the simultaneous determination of the three drugs in ternary mixture using chemometric and ANN techniques.

Multivariate calibrations are widely used in quantitative spectral analysis for compounds with highly overlapping spectra. These calibrations are characterized by the higher speed of data processing and minimizing of calibration models errors by measuring the absorbance at many points in the wavelength range of the zeroorder and derivative spectra. Control analyses on pharmaceutical preparations using multivariate calibration methods have been proven to be a valid alternative to HPLC [34]. These calibrations have been used in many analysis methods such as spectrophotometric [35], spectrofluorometric [36], and voltammetric [37] methods. In this work, three multivariate calibration methods have been described to resolve the overlapping between DIC, PAR, and CHZ in their zero-order spectra. These methods include classical least squares (CLS), principal 
component regression (PCR), and partial least squares (PLS). ANNs are computer programs designed to simulate some human brain functions using different algorithms, which can learn from experience. ANN analyses are currently perceived as an efficient and advantageous way to handle complex data and solve problems of non-linear calibration, pattern recognition, classification, prediction, and other related fields in analytical chemistry. Both linear and non-linear mapping functions can be modeled by suitably designing the network [38]. In this work, cascade-forward backpropagation ANN (CFBP-ANN) was used for the simultaneous determination of the cited three drugs in their ternary mixture with good accuracy and precision.

\section{METHODS}

\section{Instrumentation}

Shimadzu ultraviolet/visible spectrophotometer 1600 (Japan) connected to an IBM compatible computer and supported with UV probe software version 2.43 was used. The chemometric methods, CFBP-ANN, and data analysis were performed using Matlab ${ }^{\mathrm{TM}}$ software, version 7.9.0 with PLS-toolbox 2.0 and neural networks toolbox.

\section{Reagents and reference samples}

DIC, PAR, and CHZ (certified to contain 99.20\%, 99.45\%, and 99.64\%, respectively) were kindly supplied from the central laboratory of drug control-Sana'a, Yemen. Intagesic MR ${ }^{\circledR}$ tablets nominally containing DIC (50 mg), PAR (325 mg), and CHZ (250 mg) were manufactured by G.S. Pharmaceutical limited, India. Methanol used was of analytical grade.

\section{Standard solutions}

\section{Stock solutions}

Accurately weighed $20 \mathrm{mg}$ of DIC, $100 \mathrm{mg}$ of PAR, and $125 \mathrm{mg}$ of CHZ were transferred into separate $50 \mathrm{ml}$ volumetric flasks, dissolved in, and completed to volumes with methanol to obtain standard stock solutions containing $0.4 \mathrm{mg} / \mathrm{ml}$ of DIC, $2.0 \mathrm{mg} / \mathrm{ml}$ of PAR, and $2.5 \mathrm{mg} / \mathrm{ml}$ of CHZ.

\section{Working solutions}

Accurately measured aliquots $(5 \mathrm{ml})$ were transferred from each stock solution into separate $100 \mathrm{ml}$ volumetric flasks. The volume was completed with methanol to obtain working solutions containing $20 \mu \mathrm{g} / \mathrm{ml}$ of DIC, $100 \mu \mathrm{g} / \mathrm{ml}$ of PAR, and $125 \mu \mathrm{g} / \mathrm{ml}$ of CHZ.

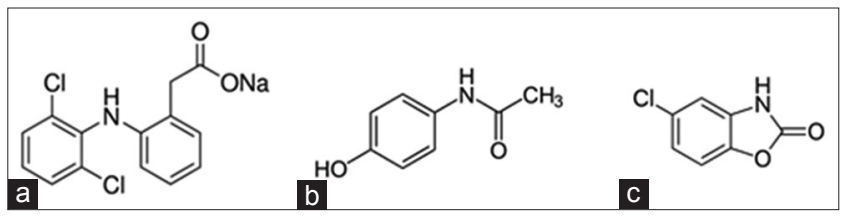

Fig. 1: Chemical structures of diclofenac sodium (a), paracetamol (b), and chlorzoxazone (c)

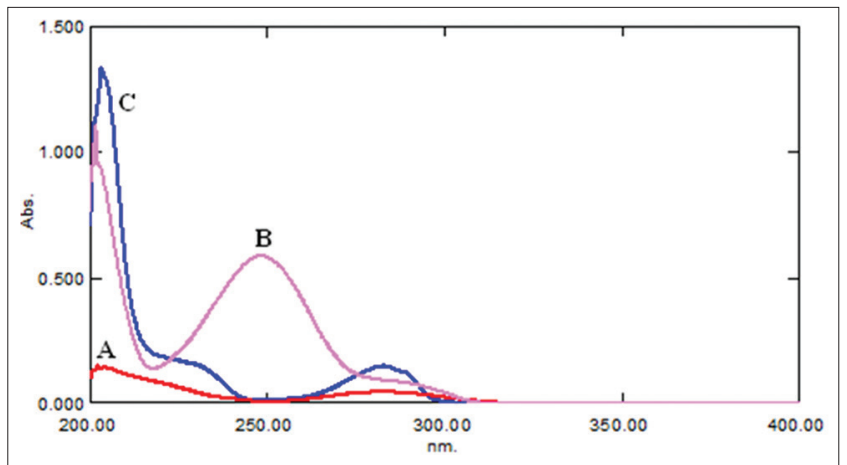

Fig. 2: Zero-order absorption spectra of diclofenac sodium $(1.0 \mu \mathrm{g} / \mathrm{ml})(\mathrm{a})$, paracetamol $(6.5 \mu \mathrm{g} / \mathrm{ml})(\mathrm{b})$, and chlorzoxazone $(5.0 \mu \mathrm{g} / \mathrm{ml})(\mathrm{c})$ in methanol

\section{Sample preparation}

Twenty tablets were accurately weighed and finely powdered using mortar and pestle. An accurate weight of the powdered tablets equivalent to $50 \mathrm{mg}$ of DIC, $325 \mathrm{mg}$ of PAR, and $250 \mathrm{mg}$ of CHZ was transferred into a $100 \mathrm{ml}$ volumetric flask. The powder was extracted with $50 \mathrm{ml}$ methanol by sonication for 15 minutes, completed to the mark with methanol, and filtered through Whatman filter paper discarding the first few milliliters to produce tablet stock solution of $0.5 \mathrm{mg} / \mathrm{ml}$ of DIC, $3.25 \mathrm{mg} / \mathrm{ml}$ of PAR, and $2.5 \mathrm{mg} / \mathrm{ml}$ of CHZ. An accurately measured aliquot $(5 \mathrm{ml})$ from the tablet stock solution was transferred into a $250 \mathrm{ml}$ volumetric flask and completed to volume with methanol to obtain the tablet working solution of $10 \mu \mathrm{g} / \mathrm{ml}$ of DIC, $65 \mu \mathrm{g} / \mathrm{ml}$ of PAR, and $50 \mu \mathrm{g} / \mathrm{ml}$ of CHZ

\section{Construction of the training set}

Twelve mixtures of DIC, PAR, and CHZ were prepared by transferring different aliquots of their working solutions into a series of $10 \mathrm{ml}$ volumetric flasks and completing the volume with methanol (Table 1). The ratio of the three drugs in their combined dosage form was taken into consideration during the construction of this set. The absorbances of these prepared mixtures were then scanned between 260 and $400 \mathrm{~nm}$ with $0.2 \mathrm{~nm}$ intervals against methanol as a blank.

\section{Construction of CLS, PCR, and PLS models}

From the obtained data, three multivariate calibration models (CLS, PCR, and PLS) were constructed. The absorbance data matrix and the concentration data matrix were used for the calibration and regression. The obtained calibrations were then used for determination of the unknown concentrations of DIC, PAR, and CHZ in their ternary mixtures and in pharmaceutical dosage form. For CLS model construction, non-zero intercepts were used. The model was constructed by the feeding of the Matlab ${ }^{T M}$ with the absorbance and concentration matrices of the training set, and then, $\mathrm{K}$ matrix was calculated. For PCR and PLS methods, PLS-toolbox 2.0 software with the training set absorbance and concentration matrices was used for the calculations.

\section{Selection of the optimum number of factors to build the PCR and PLS models}

For the selection of the optimum number of factors, cross-validation method was used leaving out one sample at a time [39]. PLS and PCR calibration on eleven calibration spectra were performed, and using this calibration, the concentration of the sample left out during the calibration process was predicted. This process was repeated 12 times until each training sample had been left out once, and all samples concentrations were predicted. The predicted concentrations of the three drugs in each sample were compared with the true concentrations in this calibration samples, and then, root-mean-square error of crossvalidation (RMSECV) was calculated for each method. The optimum number of factors was selected by visual inspection.

Table 1: The concentrations of different mixtures of DIC, PAR and $\mathrm{CHZ}$ used in the training set

\begin{tabular}{llll}
\hline Sample No. & DIC $(\mu \mathrm{g} / \mathbf{m l})$ & PAR $(\mu \mathrm{g} / \mathbf{m l})$ & CHZ $(\mu \mathrm{g} / \mathbf{m l})$ \\
\hline 1 & 1.6 & 9.4 & 8.5 \\
2 & 1.6 & 10.4 & 8.0 \\
3 & 1.6 & 11.4 & 7.5 \\
4 & 3.2 & 21.8 & 15.5 \\
5 & 3.2 & 20.8 & 16.0 \\
6 & 3.2 & 19.8 & 16.5 \\
7 & 4.8 & 30.2 & 24.5 \\
8 & 4.8 & 31.2 & 24.0 \\
9 & 4.8 & 32.2 & 23.5 \\
10 & 6.4 & 42.6 & 31.5 \\
11 & 6.4 & 41.6 & 32.0 \\
12 & 6.4 & 40.6 & 32.5 \\
\hline
\end{tabular}


RMSECV $=\sqrt{\frac{\text { PRESS }}{\mathrm{n}}}$

Where PRESS is the predicted residual error sum of squares and $\mathrm{n}$ is the number of calibration samples [40].

PRESS $=\sum\left(\mathrm{Y}_{\text {pred }}-\mathrm{Y}_{\text {true }}\right)^{2}$

Where $Y_{\text {pred }}$ and $Y_{\text {true }}$ are predicted and true concentrations in $\mu \mathrm{g} / \mathrm{ml}$, respectively.

\section{Construction of CFBP-ANN}

The same training set (Table 1) that used in CLS, PCR, and PLS was also used for training the CFBP-ANN model created in Matlab ${ }^{T M}$, version 7.9.0. CFBP-ANN which contains sigmoid layer with 10 neurons and another linear layer was found appropriate for the simultaneous determination of the three drugs in their ternary mixture (Fig. 3).

\section{Construction of the validation set}

To evaluate the prediction performance of the proposed four methods (CLS, PCR, PLS, and CFBP-ANN), nine different mixtures of DIC, PAR, and $\mathrm{CHZ}$ were prepared by transferring different aliquots of their working solutions into $10 \mathrm{ml}$ volumetric flasks and completing the volume with methanol. The ratio of the three drugs in tablets was taken into consideration during the preparation of these mixtures. The concentrations of the three drugs in these prepared mixtures were predicted using the suggested techniques.

\section{Analysis of DIC, PAR, and CHZ in Intagesic MR ${ }^{\circledR}$ tablets}

The four methods were applied to the determination of DIC, PAR, and CHZ in commercial tablets. Further dilutions of the working tablet solution with methanol were carried out to obtain concentrations of 1.6-4.4 $\mu \mathrm{g} / \mathrm{ml}$ of DIC, $10.4-28.6 \mu \mathrm{g} / \mathrm{ml}$ of PAR, and $8.0-22.0 \mu \mathrm{g} / \mathrm{ml}$ of CHZ. Standard addition technique was carried out to prove the accuracy of the proposed methods. The percentage recoveries of the drugs in the pharmaceutical dosage form and added standards were calculated.

\section{RESULTS AND DISCUSSION}

\section{CLS, PCR, and PLS}

The absorbance data in the wavelength range $267-295 \mathrm{~nm}$ with the intervals $0.2 \mathrm{~nm}$ were chosen as it provided the highest amount of information about the three drugs of this ternary mixture while the data below $267 \mathrm{~nm}$ and above $295 \mathrm{~nm}$ were rejected.

CLS model was constructed with non-zero intercept. The non-zero intercept allows an additional degree of freedom when $\mathrm{k}$ matrix is calculated. This provides an additional opportunity to adjust the effects of the extraneous substances [41]. The CLS method requires all components in the calibration samples to be known. For the PCR and PLS techniques, selection of the optimum number of factors was a very important step before constructing the models. If the number of factors retained was more than the number required, more noise would be added to the data. On the other hand, if the number retained was less than the number required, meaningful data that could be necessary for the calibration might be ignored. The optimum number of factors was selected by visual inspection. According to the Figs. 4 and 5, two factors were found suitable for both PCR and PLS methods.

\section{CFBP-ANN}

The choice of the suitable ANN was done by trying different types of ANNs that included CFBP, Elman back propagation, and radial basis networks. The CFBP-ANN was selected as it gave good results concerning accuracy and precision. Bayesian regulation training function (TRAINBR), gradient descent learning function (LEARNGD), and MSE performance were optimal for the simultaneous determination of the three drugs in their ternary mixture.

\section{Accuracy}

The accuracy was assessed by the recovery study of the three drugs in their laboratory prepared mixtures (validation set), and good mean percentage recoveries were calculated (Table 2). Accuracy of the methods was also confirmed using standard addition technique to Intagesic $\mathrm{MR}^{\circledR}$ tablets. Good mean percentage recoveries were obtained, indicating the absence of excipients interference and a good accuracy of the methods (Table 3).

\section{Precision}

The precision of the methods was assessed by studying intra- and interday variation using three concentrations $(2.4,3.0$, and $3.6 \mu \mathrm{g} / \mathrm{ml})$ of DIC, $(15.6,19.5$, and $23.4 \mu \mathrm{g} / \mathrm{ml})$ of PAR, and $(12.0,15.0$, and $18.0 \mu \mathrm{g} / \mathrm{ml})$ of CHZ, representing $80 \%, 100 \%$ and $120 \%$, respectively, in triplicate during the same day and on three consecutive days. The calculated values of $\%$ relative standard deviation for the three drugs concentrations were found to be $<1 \%$ for intra- and inter-day precision,

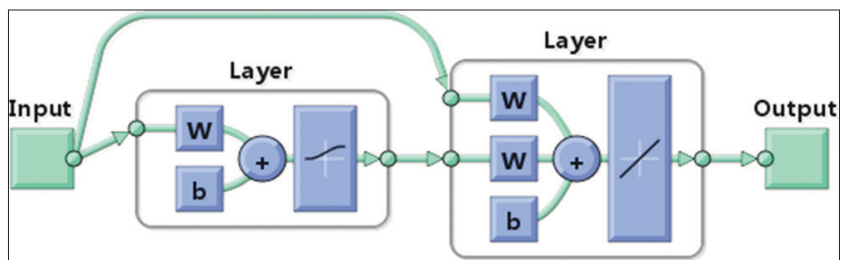

Fig. 3: Architecture of the used cascade-forward backpropagation network

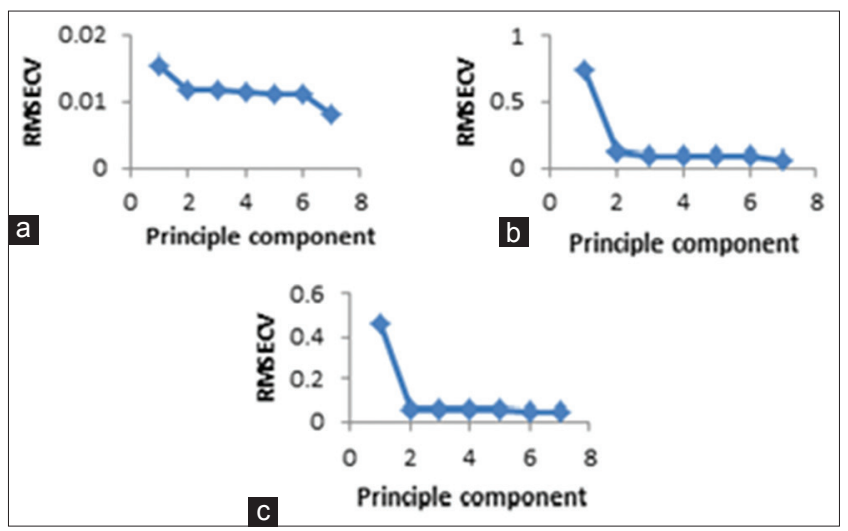

Fig. 4: Root-mean-square error of cross-validation plot as a function of the number of principle components used to construct the principal component regression model (a) diclofenac sodium, (b) paracetamol, and (c) chlorzoxazone

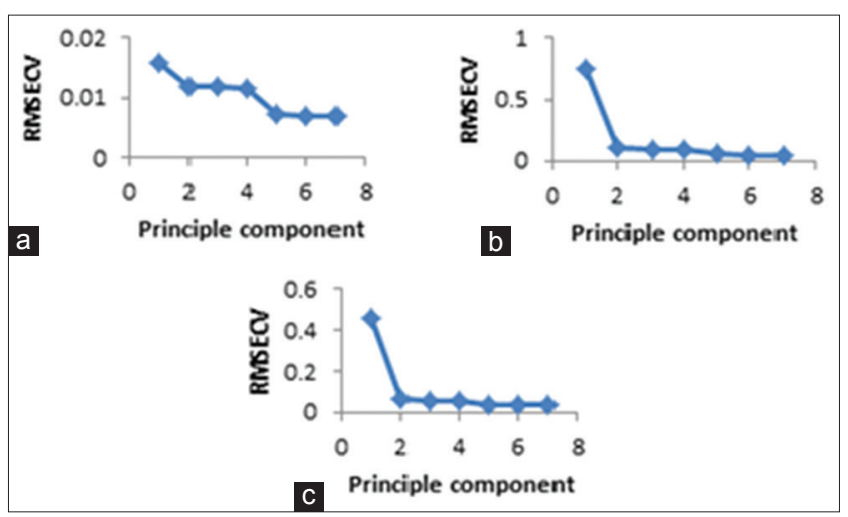

Fig. 5: Root-mean-square error of cross-validation plot as a function of the number of principle components used to construct the partial least squares model (a) diclofenac sodium, (b) paracetamol, and (c) chlorzoxazone 

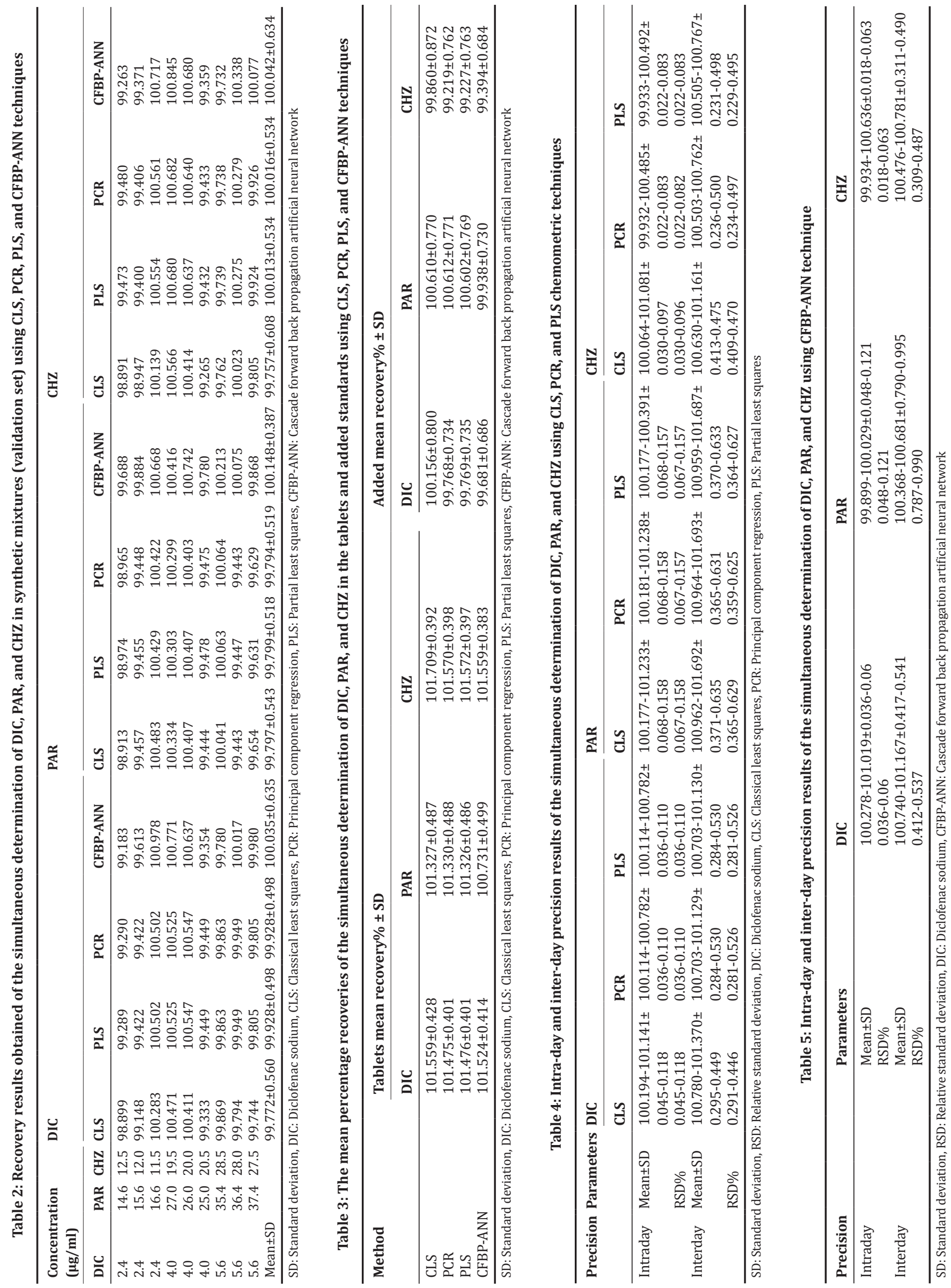


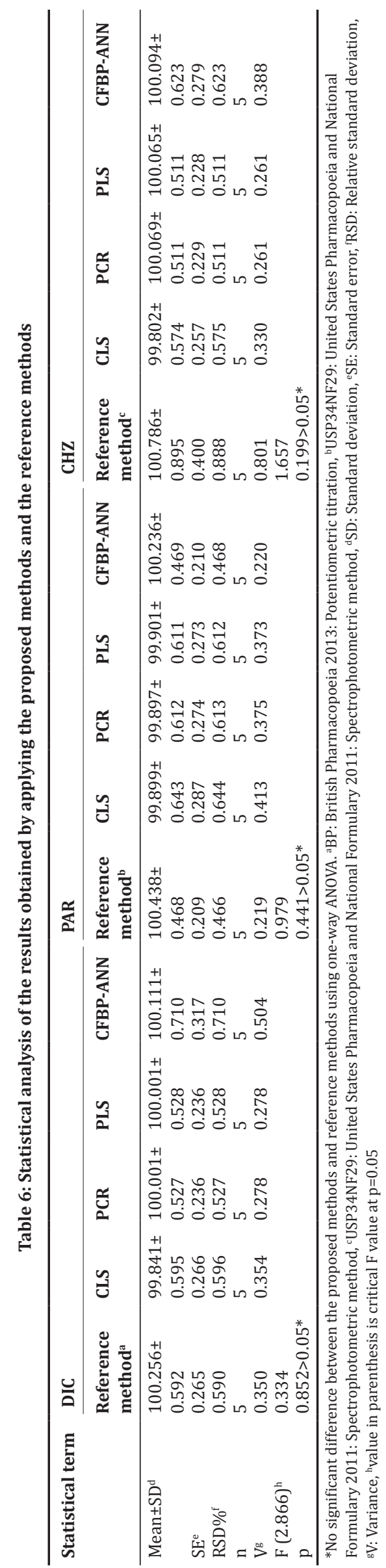

indicating that intra- and inter-day precisions of the methods as shown in Tables 4 and 5.

\section{Selectivity}

The selectivity of the four methods was evident by the good mean percentage recoveries obtained from the laboratory prepared mixtures (validation set) and from the combined dosage form (Intagesic MR ${ }^{\circledR}$ tablets) without any interference from the tablets excipients.

\section{Statistical analysis}

Statistical analysis of the recovery results obtained from the laboratory prepared mixtures using the four proposed methods and reference method for each drug was performed using one-way ANOVA. The calculated $\mathrm{F}$ values were $<$ the critical one and $\mathrm{p}$ values were $>0.05$, confirming the absence of significant difference between them concerning accuracy and precision as shown in Table 6.

\section{CONCLUSION}

The four proposed methods (CLS, PCR, PLS, and CFBP-ANN) can be used for the simultaneous determination of DIC, PAR, and CHZ in synthetic ternary mixtures and pharmaceutical dosage form containing them without interference and without the need for previous physical separation of them. Multivariate calibration models were built from the spectral and concentration data matrices. Verification of the calibrations, carried out with the aid of a synthetic set of mixtures of the three drugs, produced satisfactory results showing simplicity, selectivity, and rapidity. Hence, the proposed methods can be used for quality control of the cited drugs.

\section{REFERENCES}

1. Sweetman SC. Martindale: The Complete Drug Reference. $36^{\text {th }}$ ed. London: Pharmaceutical Press; 2009.

2. Wilson CO, Beale JM, Block JH. Wilson and Gisvold's Textbook of Organic Medicinal and Pharmaceutical Chemistry. $12^{\text {th }}$ ed. Philadelphia, PA: Lippincott Williams \& Wilkins; 2011.

3. Brunton L, Chabner B, Knollman B. Goodman and Gilman's The Pharmacological Basis of Therapeutics. 12 $2^{\text {th }}$ ed. New York: McGraw-Hill; 2011.

4. Sena MM, Chaudhry ZF, Collins CH, Poppi RJ. Direct determination of diclofenac in pharmaceutical formulations containing B vitamins by using UV spectrophotometry and partial least squares regression. J Pharm Biomed Anal 2004;36(4):743-9.

5. Charyulu RN, Ahmed MG, Nayak P, Dixit M. Simultaneous analysis and validation of ciprofloxacin-diclofenac and tetracyclinediclofenac by using UV spectrophotometer. Int J Pharm Sci Rev Res 2014;28(1):207-13.

6. Ghasemi J, Niazi A, Ghobadi S. Simultaneous spectrophotometric determination of benzyl alcohol and diclofenac in pharmaceutical formulations by chemometrics method. J Chin Chem Soc 2005;52(5):1049-54.

7. Arancibia JA, Boldrini MA, Escandar GM. Spectrofluorimetric determination of diclofenac in the presence of alpha-cyclodextrin. Talanta 2000;52(2):261-8.

8. Castillo MA, Bruzzone L. Indirect fluorometric determination of diclofenac sodium. Anal Sci 2006;22(3):431-3.

9. Yilmaz B, Ciltas U. Determination of diclofenac in pharmaceutical preparations by voltammetry and gas chromatography methods. J Pharm Anal 2015;5(3):153-60.

10. Chethana B, Basavanna S, Naik YA. Voltammetric determination of diclofenac sodium using tyrosine-modified carbon paste electrode. Ind Eng Chem Res 2012;51(31):10287-95.

11. González L, Yuln G, Volonté MG. Determination of cyanocobalamin, betamethasone, and diclofenac sodium in pharmaceutical formulations, by high performance liquid chromatography. J Pharm Biomed Anal 1999;20(3):487-92.

12. Arcelloni C, Lanzi R, Pedercini S, Molteni G, Fermo I, Pontiroli A, et al. High-performance liquid chromatographic determination of diclofenac in human plasma after solid-phase extraction. J Chromatogr B Biomed Sci Appl 2001;763(1-2):195-200.

13. Yilmaz B, Asci A, Palabiyik SS. HPLC method for determination of diclofenac in human plasma and its application to a pharmacokinetic study in Turkey. J Chromatogr Sci 2011;49(6):422-7. 
14. Emami J, Ghassami N, Talari R. A rapid and sensitive modified HPLC method for determination of diclofenac in human plasma and its application in pharmacokinetic studies. J Pharm Sci 2007;15(3):132-8.

15. Vemula VR, Sharma PK. RP-HPLC method development and validation for simultaneous estimation of diclofenac and tolperisone in tablet dosage form. Asian J Pharm Clin Res 2013;6(3):186-9.

16. Abdel-Hamid ME, Novotny L, Hamza H. Determination of diclofenac sodium, flufenamic acid, indomethacin and ketoprofen by LCAPCI-MS. J Pharm Biomed Anal 2001;24(4):587-94

17. Sparidans RW, Lagas JS, Schinkel AH, Schellens JH, Beijnen JH. Liquid chromatography-tandem mass spectrometric assay for diclofenac and three primary metabolites in mouse plasma. J Chromatogr B Analyt Technol Biomed Life Sci 2008;872(1-2):77-82.

18. Alam MA, Al-Jenoobi FI, Al-Mohizea AM. High-throughput ultraperformance LC-MS-MS method for analysis of diclofenac sodium in rabbit plasma. J Chromatogr Sci 2015;53:47-53.

19. El-Bagary RI, Azzazy HM, ElKady EF, Farouk F. UPLC-MS/MS determination of aceclofenac and diclofenac in bulk, dosage forms and in at-line monitoring of aceclofenac synthesis. Br J Pharm Res 2014;4(11):1311-31.

20. Lachmann B, Kratzel M, Noe CR. Rapid determination of diclofenac in pharmaceutical formulations by capillary zone electrophoresis. Sci Pharm 2012;80(2):311-6.

21. Krzek J, Starek M. Densitometric determination of diclofenac, 1-(2,6-dichlorophenyl)indolin-2-one and indolin-2-one in pharmaceutical preparations and model solutions. J Pharm Biomed Anal 2002;28(2):227-43.

22. Thongchai W, Liawruangrath B, Thongpoon C, Machan T. High performance thin layer chromatographic method for the determination of diclofenac sodium in pharmaceutical formulations. Chiang Mai J Sci 2006;33(1):123-8

23. Sharma R, Pathodiya G, Mishra GP, Sainy J. Spectrophotometric methods for simultaneous estimation of paracetamol and diclofenac sodium in combined dosage form by application of hydrotropic solubilization. J Pharm Sci Res 2010;2:821-6

24. Prajapati KM. Spectrophotometric estimation of chlorzoxazone and diclofenac sodium in synthetic mixture by first order derivative spectrophotometry. Int J Pharmamed India 2013;1(2):258-69.

25. Patel SA, Prajapati KM. Spectrophotometric estimation of chlorzoxazone and diclofenac sodium in synthetic mixture by Q-absorbance ratio method. Int J Chemtech Res 2013;5(4):312-23.

26. Dighe V, Sane R, Menon S, Tambe H, Pillai S, Gokarn V. Simultaneous determination of diclofenac sodium and paracetamol in a pharmaceutical preparation and in bulk drug powder by high-performance thin-layer chromatography. J Planar Chromatogr Mod TLC 2006;19(112):443-8.

27. Okoth OK, Yan K, Liu L, Zhang J. Simultaneous electrochemical determination of paracetamol and diclofenac based on poly (diallyldimethylammonium chloride) functionalized graphene. Electroanalysis 2016;28(1):76-82.
28. Gowramma B, Rajan S, Muralidharan S, Meyyanathan S, Suresh B. A validated RP-HPLC method for simultaneous estimation of paracetamol and diclofenac potassium in pharmaceutical formulation. Int J Chemtech Res 2010;2(1):676-80.

29. Patel J, Patel P. RP-HPLC method development and validation for the estimation of diclofenac sodium, tramadol hydrochloride and chlorzoxazone from their combined tablet dosage form. Int J Pharm Pharm Sci 2014;6(7):632-7.

30. Mohite VI, Potawale SE, Gabhe SY. Development and validation of HPTLC method for simultaneous estimation of paracetamol, diclofenac potassium and chlorzoxazone in bulk drug and tablet dosage form. Int $\mathrm{J}$ Pharm Pharm Sci 2013;5(2):432-5.

31. Pawar S, Kale A, Amrutkar M, Bhosale A. HPTLC estimation of paracetamol, diclofenac sodium and chlorzoxazone in tablet dosage form. Asian J Res Chem 2009;2:306-8.

32. Badgujar MA, Pingale SG, Mangaonkar KV. Simultaneous determination of paracetamol, chlorzoxazone and diclofenac sodium in tablet dosage form by high performance liquid chromatography. J Chem 2011;8(3):1206-11.

33. Mithun C, Dipanjan RC, Arindam B, Debabrata D, Susanto C. Simultaneous determination of paracetamol, chlorzoxazone and diclofenac sodium in tablet dosage form by HPLC. Int J Pharm Innov 2012;2(2):34-40

34. Blanco M, Coello J, González F, Iturriaga H, Maspoch S, Tomás X. Spectrophotometric determination of pharmaceutical dosages by partial least-squares calibration. J Pharm Biomed Anal 1994;12(4):509-14

35. Boeris, Luco JM, Olsina RA. Simultaneous spectrophotometric determination of phenobarbital, phenytoin and methylphenobarbital in pharmaceutical preparations by using partial least-squares and principal component regression multivariate calibration. J Pharm Biomed Anal 2000;24(2):259-71.

36. Pulgarín JA, Molina AA, López PF. Direct analysis of amiloride and triamterene mixtures by fluorescence spectrometry using partial-least squares calibration. Anal Chim Acta 2001;449(1):179-87.

37. Ni Y, Wang L, Kokot S. Voltammetric determination of chlorpromazine hydrochloride and promethazine hydrochloride with the use of multivariate calibration. Anal Chim Acta 2001;439(1):159-68

38. Aktaş HA, Ertokuş PG. Potentiometric determination of ibuprofen, indomethacin and naproxen using an artificial neural network calibration. J Serb Chem Soc 2008;73(1):87-95

39. Ni Y, Gong X. Simultaneous spectrophotometric determination of mixtures of food colorants. Anal Chim Acta 1997;354(1):163-71.

40. El-Gindy A. HPLC and chemometric assisted spectrophotometric methods for simultaneous determination of diprophylline, phenobarbitone and papaverine hydrochloride. Farmaco 2005;60(9):745-53.

41. Kramer R. Chemometric Techniques for Quantitative Analysis. New York: Marcel Dekker; 1998 